\title{
Comparing the Utility of Predictor Variables at University Level
}

\author{
Matthew Rudd \\ English Language Centre, Mahanakorn University of Technology, Bangkok 10530, Thailand
}

\begin{abstract}
This quantitative research study investigated the predictive utility of six separate predictor variables; selfefficacy scales, teacher ratings, prior performances, students' study habits, perceived attitudes, as well as the reliability of self-reporting instruments. Anticipated English language outcomes across all measures were compared with end-of-term scores using significance testing (0.05) and Pearson's Correlation Coefficient. The sample population consisted of 84 third year university students (females $=51$; males $=33$ ) studying at a private university located on the outskirts of Bangkok, and were from two separate faculties; business administration (n $=58)$ and engineering $(\mathrm{n}=26)$. Overall, the mean level of English language performance was $59.94 \%$, and comparative to which, the most reliable predictor of academic performance were self-efficacy scales (S.E: $60.07 \%$; not sig, $\mathrm{p}<0.05)$, which also manifested a relatively close correlation $(\mathrm{r}=0.5598)$. Likewise, teacher ratings $(57.98$, not sig, $\mathrm{p}<0.05)$ were almost as precise, and highly correlative $(\mathrm{r}=0.7068)$, but considered to be less pragmatic owing to potential subjectivity in non-experimental conditions. However, contrary to previous research, students' prior performances (54.36) were significantly inferior to end-of term attainments, despite the inference of a strong correlation $(\mathrm{r}=0.842)$. Moreover, study habits $(42.14)$ and attitudes towards English (76.31) were grossly inaccurate with minimal correlative value. Separately, results generated from self-reported instruments closely resembled the students' official grades (prior: 54.36 vs. reported: $55.37 \% ; r=0.9393$ ); notwithstanding this level of accuracy, the efficiency of this instrument may be put into question when researching debuting students with little academic history. Thus, in terms of overall dependability and practicality, self-efficacy judgments were classified as the most efficacious means of predicting academic performance.
\end{abstract}

Key Words: Self-efficacy, predictor, attainments, performance, variable

DOI: $10.7176 / \mathrm{IKM} / 9-3-07$

Publication date:March $31^{\text {st }} 2019$

\section{Introduction}

The most well researched conceptually-rich predictor variable discussed in this paper is that of self-efficacy beliefs, which forms the theoretical basis of this paper, and is benchmarked against a range of conventional predictor variables, which include; teacher ratings, prior performances, students' study habits, perceived attitudes, as well as the reliability of self-reporting instruments. Self-efficacy beliefs are summarised as people's beliefs about their capabilities to produce designated levels of performance that exercise influence over events that affect their lives ... (and) determine how people think, feel, motivate themselves and behave (Bandura 1994). According to Bandura (1986) peoples' behaviour can be better predicted by the beliefs they hold with respect to their capabilities; a claim this paper aimed to thoroughly test alongside a host of predictor variables that have also been the focus of educational research, and are discussed at length in the literature review.

Supplementing Bandura's (1986) claim that beliefs accurately project behavioural patterns, Graham and Wiener (1996) added that focusing on students' self-beliefs as a central constituent of academic motivation is founded on the theory that the beliefs that students create, develop, and hold to be true about themselves are vital forces in their success or failure in school. Zimmerman (2000) highlights that two decades of research have clearly established the validity of self-efficacy as a predictor of students' motivation and learning. Authenticating this claim, in Pajares' (2003) review of literature on the subject of self-efficacy beliefs relative to motivation and achievement in writing, Pajares states that judgments of personal efficacy play a decisive role in student behaviour owing to the influential role in determining the choices individuals make; and in such a pursuit, efficacy beliefs govern the level and intensity of the effort invested in endeavours, the perseverance to negotiate untoward obstacles that arise unexpectedly, as well as the regulation of emotional and affective influences on task performance.

Bandura (1986) explains that self-efficacy serves as a mediating mechanism of personal agency, given the mediating interplay between the founding constituents of its origin, and the influence on subsequent behaviour. The creation of self-efficacy derives from four separate sources (Bandura 1986). Firstly, mastery experiences contribute to the development of self-efficacy beliefs based on the successes and failures of prior exploits. Those 
with strengthened levels of self-efficacy are able to learn from failed attempts to enhance future effort which helps to raise levels of self-efficacy; conversely, those possessing weaker self-beliefs tend to become debilitated by negative outcomes and setbacks. Secondly, observed successes and failures of peers and social models (vicarious experiences) contribute to increasing or decreasing one's own beliefs to succeed in a similar pursuit, and, persuasive boosts and encouragement from peers (social persuasion) also contribute to nurturing one's efficacy beliefs. On the contrary, discouraging comments erode beliefs among those with a more fragile sense of self-efficacy, which are fiendishly difficult to rekindle once extinguished. Lastly, one's inability to resist the somatic adversity (affective factors) encountered during arduous tasks undermines self-efficacy development, whereas those in possession of robust self-beliefs and proficient levels of self-regulation perceive their state of affective arousal as an energising facilitator of performance (Bandura 1986). Given the central importance of self-efficacy beliefs, the instruction of self-regulatory strategies imparted to lower performing students has been demonstrated to positively reflect in consequent performances (Graham, S., \& MacArthur, C., 1988; Zimmerman, Bandura, \& Martinez-Pons, 1992). Such strategies include the instruction of goal-setting, progress recording, mnemonics, revision techniques and self-evaluation of progress.

1.1 Measuring self-efficacy beliefs: According to Bandura (1995), the guidelines for measuring self-efficacy beliefs state that items must closely correspond with the domain being investigated. Bandura (2006) accentuates that there is no all-purpose measure, given that this nature of test may have little or no relevance to the domain of functioning (p.307). Furthermore, strength of efficacy beliefs rated on a 100-point continuum (grouped in units of 10) offer more predictive utility compared to response scales comprising a limited range of answers, and are psychometrically stronger (Pajares, Hartley, \& Valiante, 2001). A more limited scale risks losing differentiating information as individuals tend to avoid extreme positions by selecting the middle value; thus the choice of more intermediate steps allows for greater variation of responses (Bandura, 2006, p.312).

The central research question in this paper is to compare the effectiveness of self-efficacy response scales with conventional predictors of achievement, which include prior performance, teacher ratings, students' attitudes, study habits and the reliability of self-reporting instruments. The precedent of publicly available research relevant to the aforementioned variables is summarised and discussed in the next section.

\section{Review of related studies}

The literature reviewed below comprises a multitude of studies that have collectively examined a range of predictor variables, inclusive of self-efficacy, self-reporting instruments, student interest, psychological resilience, study habits, gender, place of residence, and, prior performances.

2.1 The predictive value of self-efficacy scales: The first study for review was published in the Journal of Education and Practice (Feb, 2019, vol. 10, issue 4) and researched the predictive value of Bandura's 100-point self-efficacy scales among 208 third year university students at a private institute of technology in Bangkok. The students were from three separate faculties; veterinary medicine $(n=60)$, business administration $(n=77)$, engineering $(n=71)$, and, the fundamental research question was to discover the extent to which self-efficacy beliefs in English language attainments correlated with subsequent performance outcomes. Respondents were required to signpost their levels of self-efficacy in English as a general subject as well as domain in specific matters; which included speaking skills, mid-term tests and end of term examinations. The results indicated that the predictive value of subject related measures of self-efficacy proved to be highly accurate, given that the means of both variables were not significantly different ( self-efficacy $=68.12 \%$ vs. English $=66.28 \% ; p<0.05$ ), and manifested a close correlation $(\mathrm{r}=0.692)$.

However, the study showed that results from the domain-specific scales were less consistent as personal efficacy judgments with reference to speaking skills were significantly inferior to subsequent attainments (self-efficacy = 58.46 vs. English $=68.25 ; \mathrm{p}<0.05)$; which inevitably resulted in a weaker correlation $(\mathrm{r}=0.5248)$. That said, there was no significant difference between declarations of efficacy beliefs and performance outcomes in both mid-term and final examinations (self-efficacy $=62.59 \%$ vs. mid-term tests $=64.33 \%$ : $\mathrm{p}<0.05$; self-efficacy $=$ $63.22 \%$ vs. final examinations $=64.24 \% ; \mathrm{p}<0.05$ ). Furthermore, for both formal examinations, self-efficacy beliefs and consequent performance outcomes also correlated closely (mid-term exam, $r=0.7018$; final exam, $r$ $=0.686$ ).

The study also discovered that, in general terms, females stated themselves as more efficacious than male students (females $=70.68 \%$ vs. males $=64.78 \%$ ), performed at significantly higher levels (females $=69.49$ vs. males $=61.73$ ); and were more accurate in their self-efficacy judgments (females, $r=0.7257$; males, $r=0.6363$ ). A further observational remark was that higher performing students underestimated their abilities in relation to 
subsequent performance outcomes, whereas lower ability students overstated their beliefs relative to their potential.

2.2 Self-efficacy and academic self-reporting instruments: A previous study was published in the journal of European Academic Research (2013) and examined the relationship between self-efficacy and academic performance in the context of gender among Albanian students. The sample population consisted of 180 participants (females $=102$, males $=78$ ) from two major universities in the Albanian capital, Tirana. The subcluster populations comprised 60 students from year levels one, two and three (mean age: 22 years). Questionnaires were issued to measure levels of perceived self-efficacy and self-reporting instruments were utilised to collate students' current GPA scores. In this study, self-efficacy scales were scored on a limited continuum of 1-4, and on average, females displayed lower levels of self-efficacy (2.67) compared to their male peers (3.06). Despite this variance in self-efficacy beliefs, no significant difference was noted in academic performance, given that female students reported a marginally higher mean GPA of 7.75 (vis-à-vis 7.45 for male students). Overall, the correlation between self-efficacy and academic performance was remarkably close ( $\mathrm{r}=$ 0.85). Nevertheless, there are two major questions surrounding the findings produced from this study. Firstly, is whether self-efficacy beliefs between males and females would still have correlated equally if 100 point response scale was utilised; and secondly, pertains to the extent to which researchers can truly rely of self-reporting instruments as a veridical data-gathering tool. The current study aims to provide answers to both questions.

2.3 Predictive potential of student interest, psychological resilience, and study habits: The third study for discussion was published in the US-China Education Review (2011); and examined the influence of studentrelated variables as predictors of academic achievement among 131 first year psychology students in Barbados (46 males, 85 females; mean age: 28.7 years). The research instruments comprised Psychology Achievement Tests and Interest in Higher Education Scales to ascertain students' level of interest, as well as Psychological Resilience Scales and Study Habit Scales. The results revealed highly positive correlations between the studentrelated variables and academic performance. Interest in higher education was determined to be the most correlative predictor of academic achievement $(\mathrm{r}=0.583)$, although psychological resilience $(\mathrm{r}=0.556)$ and study habits $(\mathrm{r}=0.540)$ also proved to be almost equally as correlative. The student-related variables combined contributed $46 \%$ of variance in academic achievement ( $r$-square $=0.464$ ), which was considered to be significant. However, upon closer inspection, interest in education alone accounted for 34\% (R-square $=0.340)$ of the variance in academic achievement, psychological resilience accounted for $8 \%$ of this variance $(42 \%$, Rsquare $=0.420)$, whereas study habits accounted for a smaller $4 \%(\mathrm{R}$-square $=0.464)$.

However, it would also be of empirical interest to examine the interaction of profile variables within this context, such as gender and age. This would have revealed statistically telling details, as it still remains unclear which gender (or age bracket) regulated their study habits and emotional proclivities more efficiently. In light of this remark, the current study seeks to examine statistical variations according to profile demographics (gender and field of study) across a wide spectrum of predictor variables.

2.4 Predictive reliability of past performance, attendance, place of residence and gender: The fourth study appeared in the International Journal of Medicine and Public Health (Vol 4, Issue 4, 2014), and investigated a range of factors alleged to anticipate academic performance; such as previous academic performance, attendance, place of residence and gender. The study comprised 147 second year undergraduate medical students $($ male $=103$, female $=44)$ at a well-known medical institution in Kolkata (India). Better academic grades were observed for the group with high attendance percentage compared to the other with low attendance percentage ( $\mathrm{p}$ $<0.01$ ). Higher percentage of marks was also scored by female students (mean of females: 60.97 vs. mean of males: 53.61, $\mathrm{p}<0.01$ ). To determine the reliability of previous academic attainments as a means of anticipating subsequent performances, students were divided into two groups: lower performers (those who failed to clear all the subjects of 1st year) and higher performers (those who cleared all the 1st year subjects in their first attempt). The higher level performers scored significantly better in the microbiology examination in comparison to the lower level performers of the previous year $(p<0.01)$. Furthermore, the attendance of the students was considered to be an important factor, disclosing a strong association between students' performance in microbiology exams and attendance percentage. The study also concluded that attendance should be closely monitored and regulated through corrective actions in order to improve students' performance.

In relation to the place of residence and its impact on academic performance, students were divided into two subgroups; local aid $(n=50)$ and hostel aid $(n=97)$. T-tests showed that local aid students consistently outperformed students accommodated by hostel aid; 53.01 vs. 58.25 ( $\mathrm{p}<0.01$ ), and, that local students predominantly featured among the tier of students capable of successfully clearing their first year coursework 
first time round $(\mathrm{p}<0.01)$. In sum, successful performance in 1 st year (prior performance), residence (local aid) and gender altogether predict $47 \%$ of the variability of students' current academic performance.

For greater clarity, this study could have contemplated comparing past performances of each individual student with current attainments, which may have yielded different results to comparing the difference in academic standards between separate clusters divided into higher and lower achieving students.

In line with the above research, a more recent study in the European Journal of Dental Education (Vol 22, issue 2,2018 ) also tested the predictive validity of prior performances among a sample 116 oral health students along with variables such as age, gender, ethnicity, level of prior education, institute of prior education, work experience and prior academic achievement. The aim was to predict students' academic performance in the discipline-specific bioscience paper at the Auckland University of Technology from 2011 to 2014, through use of multivariable regression analysis and Pearson's Correlation Coefficient. The results determined that prior academic achievement was the only statistically significant predictor variable for the academic performance in the discipline-specific bioscience paper, $(\mathrm{r}=0.641, \mathrm{p}<0.001)$.

The significance of this study: The unique empirical contribution of this study is to cross-examine the accuracy of self-efficacy scales alongside a range of alternative predictor variables, many of which have been found to be highly correlated with academic performance. In addition to self-efficacy, this research paper examined the predictive value of prior performances in contrast with end of term attainments, along with teachers' estimations, attitudes towards English, study habits, and, assessing the dependability of self-reporting instruments. T-tests were used to calculate the level of significance between the anticipated levels of performance (as indicated by each predictor variable) and final grade outcomes in English. Pearson's Correlation Coefficient analysis was also utilised to determine the respective degree of linearity and consistency between variables. The results of these findings aim to serve as an orientation base for teachers to become familiar with new (or current) students' academic abilities as efficiently and accurately as possible, which will in turn, help to identify struggling students in need of additional instruction, and select curricular content appropriate to students' current capabilities.

\subsection{Research questions}

1. What is the students' declared level of self-efficacy in English as an academic subject?

2. What are the students' prior English language attainments?

3. What are the teachers' predictions of the students' language attainments?

4. What is the students' approach towards English in terms of (1) study habits and (2) declared attitudes?

5. What is the influence of gender and students' academic background within the above parameters?

6. How reliable are self-reporting instruments for researching students' current capabilities?

\subsection{Hypotheses}

1. Without access to student records, self-efficacy measures using a 100-point response format are expected to be the most accurate form of predicting student attainments.

2. With access to student records, past performance is expected to be the strongest predictor variable.

3. Female students are expected to estimate their levels of self-efficacy more accurately than males, and therefore score more positively across all measures.

\section{Methodology}

The sample population consisted of 84 third year university students (females $=51$; males $=33$ ) from a private higher education institute located on the outskirts of Bangkok. The students were from two separate faculties; business administration $(n=58)$ and engineering $(n=26)$. With respect to student profiles, information relating to age, gender and academic discipline were collated using self-efficacy surveys, which were anonymous and confidential. For added clarity, surveys and demonstrations were conducted in the local Thai language. 
3.1 Self-efficacy: Given the multitude of variables encompassed in this study, to simplify proceedings, selfefficacy was measured on a subject-related level and did not include domain-specific questions, despite the assertion that domain specific self-efficacy questionnaires offer greater levels of predictive value (Bandura, 2006). Domain specific questions were thoroughly examined in a prior study conducted by the author of this paper (first study discussed in literature review), in which subject related self-efficacy scales proved to be unequivocally more reliable. The findings from prior research lead to the assumption that subject-related measures of efficacy judgments are also formed on the basis of the affective factors, cognitions and prior interdomain experiences within one given sphere of activity. Using the scale below $(0-100 \%)$, respondents were required to circle the score that they believed corresponded with their end of term grade potential.

\begin{tabular}{|lccccccccccc|}
\hline $\mathbf{0}$ & $\mathbf{1 0}$ & $\mathbf{2 0}$ & $\mathbf{3 0}$ & $\mathbf{4 0}$ & $\mathbf{5 0}$ & $\mathbf{6 0}$ & $\mathbf{7 0}$ & $\mathbf{8 0}$ & $\mathbf{9 0}$ & & $\mathbf{1 0 0}$ \\
\hline $\mathrm{F}$ & $\mathrm{F}$ & $\mathrm{F}$ & $\mathrm{D}$ & $\mathrm{D}+$ & $\mathrm{C}$ & $\mathrm{C}+$ & $\mathrm{B}$ & $\mathrm{B}+$ & $\mathrm{A}$ & $\mathrm{A}$ &
\end{tabular}

Over the course of a 16-week term, the assessments for English language courses comprise three parts: mid-term tests (weighted at $20 \%$, conducted in week 8) speaking tests (30\%, week 12$)$, and end-term examinations $(50 \%$, week 16); both written examinations consist of reading, writing and grammar based sections. In keeping with Bandura's assertion that self-efficacy surveys must be completed prior to assessments, students filled out the questionnaires in the third week of term. Seeing that students were currently in their third year of study, they were very familiar with the demands of the course content and formal assessments, and were therefore well placed to judge their capabilities in this context. Their efficacy judgments were then compared with the final grade outcomes using both t-tests, to ascertain the level of significance between both means, and Pearson's Correlation Coefficient to determine the degree of linearity between variables.

3.2 Prior performances: The university registrar provided final grade outcomes from the previous English courses, and these prior scores were contrasted with end-of-term performances. Itemised data concerning speaking assessments and individual examination scores were not available as students' end-of-term results are archived as one overall percentage score, which will subsequently be compared with students' declarations of self-efficacy, also measured on the basis of anticipated levels of overall achievement.

3.3 Teacher ratings: Three teachers, including the researcher, partook in this experiment. Out of ten faculty members, the three selected were those who demonstrated a thorough understanding of their students on an individual basis. Further to the very primitive requirement of being familiar with students' names, teachers were also well-informed of students' strengths, weaknesses, personal (and academic) interests, and future plans. In week 7, one week prior to mid-term tests and after teachers had strengthened their acquaintance with students, they were asked to predict academic attainments using the same 100-point scales. Estimations were then contrasted with final grade outcomes at the end of term. It must also be noted that comparisons according to class were not considered, as the concept of this instrument is to measure predictive utility, rather than to competitively cross-compare the accuracy of the teachers' personal estimations.

3.4 Study habits: The survey also aimed to ascertain the level of engagement of the students using a similar scale canvassing for time devoted to extra-curricular study of English per week.

\begin{tabular}{|c|c|c|c|c|c|c|c|c|c|c|}
\hline 0 & 10 & 20 & 30 & 40 & $\mathbf{5 0}$ & 60 & 70 & 80 & 90 & 100 \\
\hline Zero & & & & & $5 \mathrm{hrs}$ & & & & 3 & $\mathrm{hrs}+$ \\
\hline
\end{tabular}

English constitutes a minor subject of all degree programmes, therefore three hours of autodidact tuition dedicated to English was considered to be highly efficacious. Using the same scales as above, students were asked to indicate how much of their additional study time was allotted to reading English, listening to extracts (this may include music, if lyrics are studied), movies (if new vocabulary is carefully annotated), interacting with native speakers (entirely in English), language classes, and social media (with attention paid to new language items).

3.5 Students' Attitudes: This section of the scale solicited declarations of the respondents' personal preference for the language, as well as its level of importance to them personally and vocationally. Intuitively therefore, higher values of these measures denote (1) higher levels of immersion in the subject, (2) a greater degree of perceived importance, and, (3) a greater appreciation for English as a vocational tool.

3.6 Self-reporting: Although this is not conventionally categorised as a predictor of academic performance, a number of studies however, (including the Albanian study reviewed a priori), have relied on reporting 
instruments to measure current levels of academic performance. This paper examines the accuracy of selfreporting instruments as a means of base-lining students' academic performance for research purposes; very little research has investigated this issue.

\section{Findings / Results}

Through comprehensive statistical analysis, this section addresses a multitude of research questions, which looked to cross-examine the predictive value of self-efficacy scales with the following predictor variables: (1) prior English language attainments, (2) teachers ratings, (3) extra-curricular study habits, (4) attitudes towards English, (5) the respective statistical variations according to profile demographics; and separately, (6) the reliability of self-reporting instruments.

Table 1: End of term English language scores vs. all predictor variables $(\mathrm{N}=84)$

\begin{tabular}{|l|l|l|l|l|l|}
\hline English & Variable & M & P & Result & R \\
\hline \multirow{2}{*}{\begin{tabular}{c} 
Mean of $N$ 5.94 \\
\cline { 2 - 6 }
\end{tabular}} & Self-efficacy & 61.07 & 0.339 & $\begin{array}{l}\text { Not sig } \\
\mathrm{p}<0.05\end{array}$ & 0.5598 \\
\cline { 2 - 6 } & $\begin{array}{l}\text { Prior } \\
\text { performance }\end{array}$ & 54.36 & 0.026 & $\begin{array}{l}\text { Sig } \\
\mathrm{p}<0.05\end{array}$ & 0.842 \\
\cline { 2 - 6 } & $\begin{array}{l}\text { Teacher } \\
\text { ratings }\end{array}$ & 57.98 & 0.248 & $\begin{array}{l}\text { Not sig } \\
\mathrm{p}<0.05\end{array}$ & 0.7068 \\
\cline { 2 - 6 } & Study habits & 42.14 & $<0.01$ & $\begin{array}{l}\text { Sig } \\
\mathrm{p}<0.05\end{array}$ & 0.1243 \\
\cline { 2 - 7 } & Attitudes & 76.31 & $<0.01$ & $\begin{array}{l}\text { Sig } \\
\mathrm{p}<0.05\end{array}$ & 0.2516 \\
\hline
\end{tabular}

In accordance with the reviewed literature, Table 1 shows that self-efficacy measures on a subject-related basis were highly accurate as the means between the students' final grades and efficacy judgments were almost identical (not sig: $\mathrm{p}<0.05$ ); nonetheless, teacher ratings appeared to be similarly accurate. Upon closer inspection, the greater value of $\mathrm{p}(0.339)$ associated with self-efficacy judgments infers that this predictor variable may have been minimally more accurate than teacher ratings $(\mathrm{p}=0.248)$; nevertheless, teacher ratings correlated more closely with students' attainments ( $\mathrm{r}=0.7068$ vs. S.E, $\mathrm{r}=0.5598)$, suggesting more consistency between the two variables. Interestingly, students' end-of-term attainments were significantly higher than their prior performances (sig: $\mathrm{p}<0.05$ ). The close correlation may be explained by the fact that the margin of improvement was similar among most students (e.g. most improving in the region of 5\%), however, incompatible with previous literature, this measure did not prove to be comprehensively reliable.

The variables of negligible predictive value were those of study habits and students' attitudes; the obvious reason for this pertains to the difficulty in harmonising abstract measures with concrete parameters. Despite the evident assumption that motivated students are in possession of solid study habits and inevitably achieve higher attainments, in conflict with prior literature (see US China Education Review), the data displayed in Table 1 would not associate study habits with a given level of achievement. Firstly, the findings above denoted a weak correlation and a great statistical difference between the two corresponding sets of results, and secondly, the reviewed study in question calculated that declared study habits allegedly accounted for only $4 \%$ of the variance in academic achievement. 
Table 2: The variability of results according to gender

\begin{tabular}{|c|c|c|c|c|c|c|c|c|c|c|c|c|}
\hline \multirow[b]{2}{*}{ Gender } & \multicolumn{2}{|c|}{ English } & \multicolumn{2}{|c|}{ Self-Efficacy } & \multicolumn{2}{|c|}{ Prior Performance } & \multicolumn{2}{|c|}{ Teacher Ratings } & \multicolumn{2}{|c|}{ Study habits } & \multicolumn{2}{|c|}{ Attitudes } \\
\hline & $\mathrm{F}$ & M & $\mathrm{F}$ & M & $\mathrm{F}$ & M & $\mathrm{F}$ & M & $\mathrm{F}$ & M & $\mathrm{F}$ & M \\
\hline Mean & 60.2 & 59.55 & 60 & 62.73 & 55.27 & 52.94 & 61.96 & 51.82 & 37.25 & 49.7 & 71.96 & 83.03 \\
\hline$($ Mean N) & \multicolumn{2}{|c|}{$(59.94)$} & \multicolumn{2}{|l|}{$(60.07)$} & \multicolumn{2}{|l|}{$(54.36)$} & \multicolumn{2}{|l|}{$(57.98)$} & \multicolumn{2}{|c|}{$(42.14)$} & \multicolumn{2}{|l|}{$(76.31)$} \\
\hline $\mathrm{P}$ & 0.472 & 0.462 & 0.344 & 0.279 & 0.382 & 0.333 & 0.084 & 0.041 & 0.15 & 0.087 & 0.081 & 0.021 \\
\hline Result & not sig & not sig & not sig & not sig & not sig & not sig & not sig & sig & not sig & not sig & not sig & sig \\
\hline
\end{tabular}

In concert with one previously reviewed study (regarding Albania), Table 2 also exhibits how female students reported slightly lower levels of self-efficacy, and, performed to a narrowly higher standard. And, contrary to prior findings (University of Auckland / Kolkata), prior performance did not offer a solid indication of current academic capabilities relative to gender. Separate calculations revealed that male students' mean end-term scores improved with near significance $(52.94$ vs. 59.55 ; not sig; $\mathrm{p}=0.0611)$, while the progress of female students was more marginal, as denoted in the higher value of $p(55.27$ vs. 60.2: not sig; $p=0.104)$. This transpired despite the fact that teachers bestowed significantly higher levels of trust in female students compared to male students $(61.96$ vs. $51.82 \%=\operatorname{sig}$; p < 0.05$)$, notwithstanding female students' declarations of significantly less dedicated study habits $(37.25$ vs. $49.7=$ sig; p <0.05) and lower esteem of the subject's importance $(71.96$ vs. $83.03 \%=$ sig; p <0.05). From the results displayed in Table 2, no clear inferential observations became apparent regarding the latter two variables, given that male students scored considerably higher in relation to study habits and attitudes for the subject, yet, their corresponding end-of-term attainments were still (slightly) inferior.

Table 3: The variability of results according to faculty

\begin{tabular}{|l|l|l|l|l|l|l|l|l|l|l|l|l|l|l|}
\hline & \multicolumn{2}{l|}{ English } & \multicolumn{2}{l|}{ Self-Efficacy } & \multicolumn{2}{l|}{ Prior Performance } & \multicolumn{2}{l|}{ Teacher Ratings } & \multicolumn{2}{l|}{ Study habits } & \multicolumn{2}{l|}{ Attitudes } \\
\hline Faculty & Bus & Engin & Bus & Engin & Bus & Engin & Bus & Engin & Bus & Engin & Bus & Engin \\
\hline Mean & 60.53 & 58.61 & 58.96 & 65.76 & 53.62 & 56 & 59.48 & 54.61 & 35.68 & 56.53 & 71.98 & 85.96 \\
\hline (Mean N) & $(59.94)$ & $(61.07)$ & $(54.36)$ & & \multicolumn{2}{|l|}{$(57.98)$} & $(42.14)$ & $(76.31)$ \\
\hline P & 0.431 & 0.387 & 0.207 & 0.617 & 0.399 & 0.327 & 0.297 & 0.193 & 0.072 & 0.009 & 0.072 & 0.003 \\
\hline Result & not sig & not sig & not sig & not sig & not sig & not sig & not sig & not sig & not sig & sig & not sig & sig \\
\hline
\end{tabular}

Table 3 shows a similar nature of results to those observed in Table 2, possibly due to the fact that business students are predominantly female, and engineers are mostly male students. The slight variation noted between Tables 2 and 3 are merely due to the representation of the minority gender demographic in each group. The most noteworthy variations are those of self-efficacy measures, as engineers judged their beliefs to be higher than their business counterparts (58.96 vs. 65.76 : $\mathrm{sig}, \mathrm{p}=0.0229)$. This may also be due to the possibility that female engineers are more self-efficacious than female business students, potentially owing to the mastery of managing the issues associated with cultural labelling (also referred to as gender-orientation; Eisenberg et al., 1996), and performing competitively in a male-orientated subject. This conjecture may also account for declarations of more robust study habits and more positive attitudes towards English among engineers.

Table 4: The accuracy of self-reported attainments

\begin{tabular}{|l|l|l|l|l|}
\hline English & M & P & Result & R \\
\hline Official & 54.36 & & & \\
\hline & & 0.34 & Not Sig, $\mathrm{p}<.05$ & 0.9393 \\
\hline Reported & 55.37 & & & \\
\hline
\end{tabular}


Table 4 confirms that self-reported instruments utilised to canvass for students' current level of English performance proved to be highly accurate and directly correlated (not sig: $p=<0.05 ; \mathrm{r}=0.9393$ ). This confirms that self-reporting instruments proved to constitute a dependable research instrument within the parameters studied. Researchers without immediate access to students' current English grades may contemplate utilising this tool to ascertain students' current levels of English proficiency. However, in both the Albanian study and this research paper, the respondents were third year university students who would have been aware of prior performances due to their academic history at the university. This instrument is less likely to offer statistical depth with newly arriving students (first years) or at pre-university level where students are not required to sit regular modular exams specific to their academic interests; further research may confirm this remark.

\subsection{Further discussion}

In light of the statistics analysed, the following discussion will seek to clarify a number of complex issues, such as the validity of the hypotheses, the limitations associated with this study, potential angles for successive research interventions and further reflection on the utility of all predictor variables.

Contrary to the hypothesis stated earlier, with or without access to student records of prior academic achievement, 100 point self-efficacy scales proved to be the most highly reliable predictive instrument regardless of the situational dynamics; closely followed by teacher ratings. Nonetheless, it must be pointed out that not all teachers are fully invested in their students to closely anticipate their end-of-term grades. The teachers in this study were highly aquatinted with the students in their class, and were selected especially. The ideal population of educators to investigate is that of the average teacher, and their respective capacity to predict their students' outcomes, and extending the scope of research to cover a larger number of teaching staff would inevitably include partially disengaged or less observant teachers, and would test this notion more rigorously.

With reference to students' perceived levels of self-efficacy, two separate studies in succession dedicated to testing the predictive value of self-efficacy scales have confirmed the accuracy of such a measure (in a Thai context), as well as the reported findings from an Albanian setting (as reviewed earlier); despite the latter implementing efficacy response scales with a limited continuum of 1-4. The combination of these findings, in conjunction with theories posited by high-standing academics, consolidates the assumption that self-efficacy scales constitute a very time-efficient and accurate means of determining students' current level of performance.

As far as gender is concerned, the hypothesis formed was that females' self-efficacy judgments would be more accurate, and would score higher across all measures; which was almost, but not entirely the case. While females did estimate their levels of self-efficacy slightly more accurately than their male counterparts, achieved a narrowly higher level of performance, and were granted higher levels of esteem from their respective teachers; females' attitudes to English and declared study habits were less encouraging than those stated by male students, therefore the hypothesis stipulating that females would score higher across all measures cannot be entirely validated. Further studies could consider investigating university students' attitudes towards English, their views on the associated target language culture and their perceptions of its vocational importance. This could be realised by implementing a more varied array of instrumentation, such as interviews and response coding for greater depth and specificity.

The additional question this paper examined was the utility of self-reporting instruments, which proved to be very precise. While this measure was highly correlative with current academic performance, it is constricted by one particular limitation as mentioned earlier. The accuracy of this instrument could be put into question in the event that the sample population consisted of first year students who lack relevant academic history and experience, or among more junior scholars yet to dedicate themselves to a specific discipline of personal interest.

The same could also be said for past performances and teacher ratings, but not necessarily for self-efficacy, as the latter should still prove to be highly predictive even among debutant students, as the concept refers to the level of certainty in performing a task. Supposing first year students were fully briefed on assessment criteria ahead of sitting examinations, self-efficacy judgments would still presumably prove to be highly accurate, as self-efficacy measures offer predictive advantages when tasks are familiar (Zimmerman, 2003). For added certainty, this could form the basis of a subsequent line of inquiry. 


\section{Conclusions}

With respect to the predictor variables examined in this paper, most results are subject to influence by external intervening factors. The individual subjectivity of the teacher naturally leads to partisan judgments, as manifested in the disproportionate levels of misplaced confidence in female students' capabilities. Furthermore, static past performances (if such records are available to researchers), may have been influenced by dissimilar situational dynamics on previous occasions, and do not necessarily interact in current performances. This also wrongly assumes that students are not capable of improving academically in future endeavours. With regards to attitudes or habits, these notions are abstract in nature and cannot directly be compared to concrete measurable attainments, therefore limiting their validity. Reporting instruments, notwithstanding their accuracy, require students to possess relevant academic experience in a specific institution; thus limiting the freedom with which this instrument can be implemented. If constructed and conducted properly self-efficacy judgments have proven to be the most practical and dependable predictor of academic performance. By ascertaining confidence levels and the expected performance outcomes of a given population of students, educators can identify and introduce developmentally appropriate curricular content to optimise learning potential.

\section{References}

1. Bandura, A. (1989). Social cognitive theory. In R. Vasta (Ed.), Annals of child development, vol. 6. Theories of Child Development (pp. 1-60). Greenwich, CT: JAI Press.

2. Bandura, A. (1994). Self-efficacy. In V. S. Ramachaudran (Ed.), Encyclopedia of human behavior, 4, (pp.71-81). New York: Academic Press. (Reprinted in H. Friedman [Ed.], Encyclopedia of mental health. San Diego: Academic Press, 1998).

3. Bandura, A. (1995). Guide for constructing self-efficacy scales. Available from Frank Pajares, Division of Educational Studies, Emory University, Atlanta, GA, 30322.

4. Bandura, A. (1997). Self-efficacy: The exercise of control. New York: Freeman.

5. Bandura, A. (2006). Self-Efficacy Beliefs of Adolescents, (pp. 307-337).

6. Eisenberg, N., Martin, C. L., \& Fabes, R. A. (1996). Gender development and gender effects. In D. C. Berliner \& R. C. Calfee (Eds.), Handbook of educational psychology. (pp. 358-396).

7. Graham, S., \& Weiner, B. (1996). Theories and principles of motivation. In D. C. Berliner \& R. C. Calfee (Eds.), Handbook of educational psychology (pp. 63-84). New York: Simon \& Schuster. Macmillan.

8. Graham, S., \& MacArthur, C. (1988). Improving learning disabled students' skills at revising essays produced on a word processor: Self-instructional strategy training. Journal of Special Education, 22, (pp. 133152).

9. Pajares, F., Hartley, J., \& Valiante, G. (2001). Response format in writing self-efficacy assessment: Greater discrimination increases prediction. Measurement and Evaluation in Counseling and Development, 33(4), (pp. 214-22).

10. Pajares, F. (2003). Self-efficacy beliefs, Motivation and Achievement in Writing: A review of the literature. Reading \& Writing Quarterly, 19, (pp. 139 - 158).

11. Rudd, M. (2019). Measuring the Correlation between Self-Efficacy Beliefs and English Language Attainments among Thai University Students. Journal of Education and Practice, 10(4).

12. Zimmerman, B. J., Bandura, A., \& Martinez-Pons, M. (1992). Self-motivation for academic attainments: The role of self-efficacy beliefs and personal goal setting. American Educational Research Journal, 29, (pp. 663676).

13. Zimmerman, B. (2000). Self-Efficacy: An Essential Motive to Learn, Contemporary Educational Psychology, 25, (pp. 82-91). 